\title{
Study of axial stress distribution on the buried-pipeline in longwall coal mining
}

\author{
Guoming Cheng ${ }^{1, a}$ kunyuan Wang ${ }^{2, b}$ He Peiyong ${ }^{1, c}$ Cui Li $i^{3, d}$ \\ ${ }^{1}$ China Institute of Geo-environment Monitoring, Beijing 100081, China \\ ${ }^{2}$ Guangzhou Real Estate Development Co., Ltd, Guangzhou 510627, China \\ ${ }^{3}$ China University of Mining and Technology, Beijing 100083, China \\ a1280983675@qq.com, b505581096@qq.com, c475524252@qq.com,d79502787@qq.com
}

Keywords: surface subsidence; buried pipeline; longwall mining; stress distribution

Abstract. Taking one coal mine in Shanxi section of the west-east gas pipeline as case study, numerical modeling was adopted to study the axial stress distribution on the buried-pipeline in longwall mining. The stress distribution of the simulated pipeline coincides with the monitoring results. The results revealed that(1)the axial stress distribution on the pipeline is closely related to the distance of face advancing, it undergoes three stage evolution processes, including stress gradually increasing stage, stress concentration stage and local stress exceeding limitation stage. The stress distribution on the pipeline at the three stages are described. (2)The possible damage to the pipeline occurs at the two peak tensile stresses, which are at the outer edge of gob, then at the two peak compressive stresses, which are at the inner edge of gob. (3)The possible damage to the pipe section due to peak tensile stresses is at the top, the middle and the bottom in turn, and the possible damage to the pipe section due to peak compressive stresses is at the bottom, the top and the middle in turn. The results provided theoretical basis for the layout of the pipeline monitoring network across subsidence areas.

\section{Introduction}

Researches on the deformation and the stress distribution on the buried pipeline caused by mining have been conducted [1-9]. H.WANG et al. [1] evaluated the pipeline safety by comparison of the maximum settlement of a moving basin with the maximum allowable settlement of a pipeline. K.ZHU [2] studied the influence of surface movement on the pipeline in longwall mining by the method of similar material simulation. S.S Peng et al. [3] determined the magnitude and location of the maximum stresses on the pipeline by the PFIM (probability function integration method). X.1 Wang et al. [6] used PFIM to predict deformation of the subsidence area and deduce the deformation compatibility equation of pipeline elongation, thus working out the stress and strain on the pipeline axis by iteration computation. G.M Cheng et al. [7-9] studied the stress distribution on the pipeline in steep mining using numerical analysis method.

Some achievements on deformation and stress mechanism of the pipeline due to coal mining have been obtained. However, the influence of the final surface subsidence on the deformation and stress on the pipeline has been paid close attention to, while the impacts of ground subsidence on the stress on the pipeline at different subsidence stages has not been taken into account.

Such problems, how the stress on the pipeline are distributed under different subsidence process, are still unknown so far. The above problems need to be answered in order to prevent possible damage to the pipeline.

Take one mine in Shanxi section along west-east gas pipeline as case study, FLAC ${ }^{3 \mathrm{D}}$ was adopted to study the stress distribution on the pipeline at different stages in longwall mining, which provides the guide for the layout of monitoring network of buried pipeline across subsidence areas. 


\section{Description of Background Project}

The coal mine in Shanxi section of west-east gas pipeline is taken as case study. The general dip of the coal seam is approximately horizontal. The average thickness of the coal seam is around $5.6 \mathrm{~m}$. The burial depth of coal seam is about $165 \mathrm{~m}$. The longwall panels are approximately $150 \mathrm{~m}$ wide, and longwall mining with roof caving was used. The diameter of the pipe is $1016 \mathrm{~mm}$ with the wall thickness of $21.0 \mathrm{~mm}$, and the pipeline was laid underneath the covering soil of about $3.0 \mathrm{~m}$. The allowable stress of the pipe material is $4.3 \times 10^{8} \mathrm{~Pa}$. The mechanical and physical parameters of the rock mass is shown in table 1 . The stress measurement on the pipeline was started by Beijing Keli Huangan geo-hazards Monitoring Corporation in June, 2006.

Tab.1 Mechanical and physical parameters of the rock mass

\begin{tabular}{|c|c|c|c|c|c|c|}
\hline $\begin{array}{l}\text { Name of } \\
\text { material }\end{array}$ & $\begin{array}{l}\text { Density } \\
\left(\mathrm{kg} / \mathrm{m}^{3}\right)\end{array}$ & $\begin{array}{l}\text { Bulk modulus } \\
\qquad(\mathrm{GPa})\end{array}$ & $\begin{array}{l}\text { Shear modulus } \\
\text { (GPa) }\end{array}$ & $\begin{array}{l}\text { tensile strength } \\
(\mathrm{MPa})\end{array}$ & $\begin{array}{l}\text { cohesion } \\
(\mathrm{MPa})\end{array}$ & $\begin{array}{c}\text { internal } \\
\text { frictional angle } \\
\left({ }^{\circ}\right)\end{array}$ \\
\hline overburden & 1640 & 0.25 & 0.09 & 0.1 & 0.55 & 22 \\
\hline Fine sandstone & 2530 & 2.8 & 1.6 & 4.0 & 3.5 & 33 \\
\hline Medium sand & 2560 & 3.0 & 2.5 & 3.2 & 4.0 & 30 \\
\hline siltstone & 2700 & 4.5 & 5.0 & 2.5 & 3.2 & 33 \\
\hline mudstone & 2250 & 5.6 & 4.2 & 1.5 & 2.2 & 27 \\
\hline Coal seam & 1450 & 3.0 & 1.5 & 0.9 & 2.0 & 29 \\
\hline $\begin{array}{c}\text { quartz } \\
\text { sandstone }\end{array}$ & 2660 & 5.7 & 3.4 & 3.2 & 4.0 & 30 \\
\hline
\end{tabular}

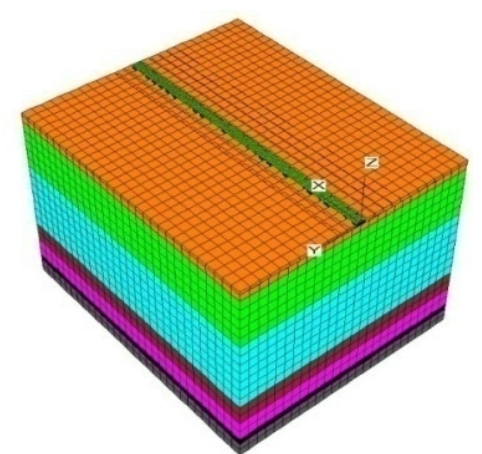

Fig.1 The numerical simulation model

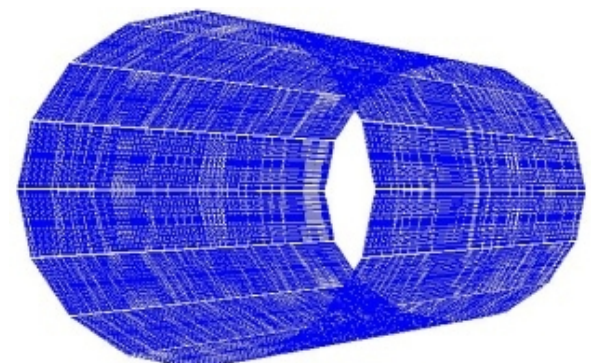

Fig.2 Enlargement of pipe grid

\section{Numerical Analysis}

\section{Computation Model}

The model length along the pipeline for calculation was $300 \mathrm{~m}$ and the width of the vertical pipeline was $250 \mathrm{~m}$ with the height of $188 \mathrm{~m}$. the shell element was used to model the pipe in the model. The model includes 3856 nodes and 7680 zones of the pipeline, and 28652 nodes and 24000 zones of rock and soil. The model grid adopted in the calculation is presented in Fig.1, and Fig.2 shows enlargement of the pipe grid. In order to simplify calculation in this research, Mohr-Coulomb Constitutive model was adopted for geotechnical materials and elastic model was adopted for the pipeline. In the calculation, stress caused by gravity was considered according to the field stress. Lateral boundary was restrained horizontally and bottom boundary was restrained vertically in the model. In the model mining process was divided into seven steps with each step of $30 \mathrm{~m}$.

\section{Analysis of Numerical Results}

\section{Axial stress distribution on the pipeline}

Partial results are seen due to space limitations. The axial stress distribution on the pipeline is shown in Fig.3. After mining the fourth step,the MTS (maximum tensile stress) and the MCS (maximum compressive stress) on the pipeline is about $2.6 \times 10^{7} \mathrm{~Pa}$ and $2.4 \times 10^{7} \mathrm{~Pa}$ respectively, and the stress curve on the pipeline shows funnel shape in Fig.3(a). After mining the fifth step, the stress 
curve also shows funnel shape in Fig.3(b). The MTS on the pipeline is about $3.5 \times 10^{7} \mathrm{~Pa}$, and increases $34.61 \%$ compared with mining the fourth step, which is 8.1 percent of allowable stress, and the MCS on the pipeline is $3.3 \times 10^{7} \mathrm{~Pa}$ with increasing $37.50 \%$ compared with mining the fourth step, accounting for $7.7 \%$ of the allowable stress.

After mining the sixth step, the stress curve on the pipeline changes from a funnel to a $U$ shape in Fig.3(c). Three stress concentration zone occurred on the pipeline, in which the peak tensile stress on the left side of the pipeline increases about 15 times, which is about $25.6 \%$ of its allowable stress, and the peak tensile stress on the right side is about $7.50 \times 10^{7} \mathrm{~Pa}$, which is 13.3 percent of the allowable stress. The peak tensile stress appears at about $38 \mathrm{~m}$ and $243 \mathrm{~m}$ of the axial direction of the pipeline, Located at the outer side of the mined out area $(45 \mathrm{~m}-225 \mathrm{~m})$. whereas the MCS is $7.3 \times 10^{7} \mathrm{~Pa}$, which is $16.9 \%$ of the allowable stress, located in mined out area.

After mining the seventh step, the stress curve on the pipeline also presents a U shape in Fig.3(d) . Four stress concentration zone occurred on the pipeline, in which the peak tensile stress on the left side of the pipeline is about $4.6 \times 10^{8} \mathrm{~Pa}$, which is $106 \%$ of the allowable stress, beyond the allowable stress. The peak tensile stress on the right side is about $5.2 \times 10^{8} \mathrm{~Pa}$, which is $120 \%$ of the allowable stress, far beyond the allowable stress. The peak tensile stress appears at $30 \mathrm{~m}$ and $269 \mathrm{~m}$ of the axial direction of the pipeline, Located at the outer side of the mined out area $(45 \mathrm{~m}-255 \mathrm{~m})$. whereas the peak compressive stress on the left side is $2.8 \times 10^{8} \mathrm{~Pa}$, which is $65 \%$ of the allowable stress, and the peak compressive stress on the right side is $2.1 \times 10^{8} \mathrm{~Pa}$, which is $49 \%$ of the allowable stress, which appears at $69 \mathrm{~m}$ and $232 \mathrm{~m}$ of the axial direction of the pipeline, Located in mined out area. The stress distribution of the simulated pipeline coincides with the monitoring results. On August 5, 2009 several axial tensile stresses were monitored over $4.36 \times 10^{8} \mathrm{~Pa}$ allowable stresses, then emergency rescue plan was started immediately to uplift the pipe section with the pressure, and at present the pipeline is still in a safe state.

In conclusion, the stress magnitude in the axial direction of the pipeline is closely related to the advancing distance of the working face. As the advancing distance increases, the stress on the pipeline along the axial direction of the pipeline undergoes three stages, namely, the stress gradually increasing stage, and the stress concentrates to the local stress exceeding limit. After mining the first to fifth steps, the pipeline stress increases gradually with the advancing distance, and the pipeline is in the extremely low stress state; after mining the sixth step, local stress of the pipeline increase, and three stress concentration zones occur, in which the peak tensile stress on the left side jumped about 15 times than mining the fifth step, but the pipeline is still in low stress condition. After mining the seventh step, the pipeline stress is changed from low stress to local stress exceeding limit, and emergency treatment measures are needed.

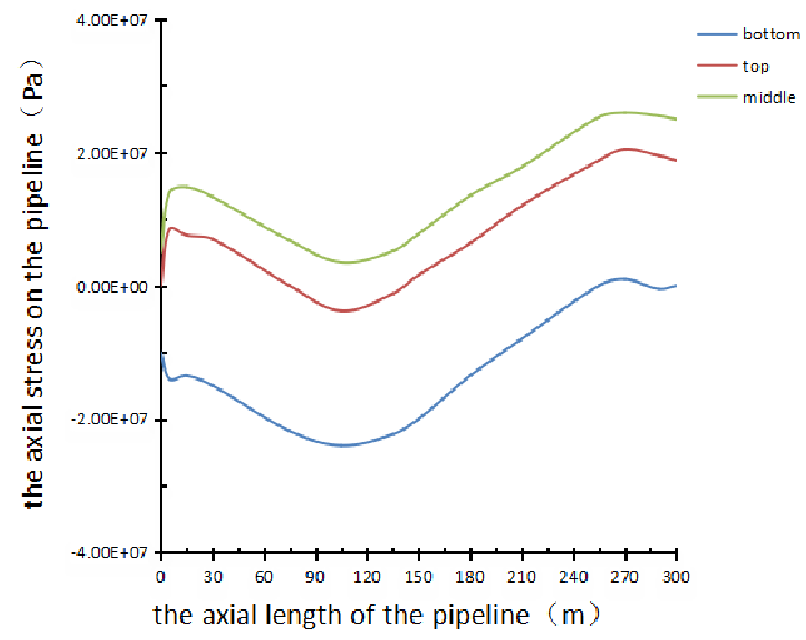

(a)

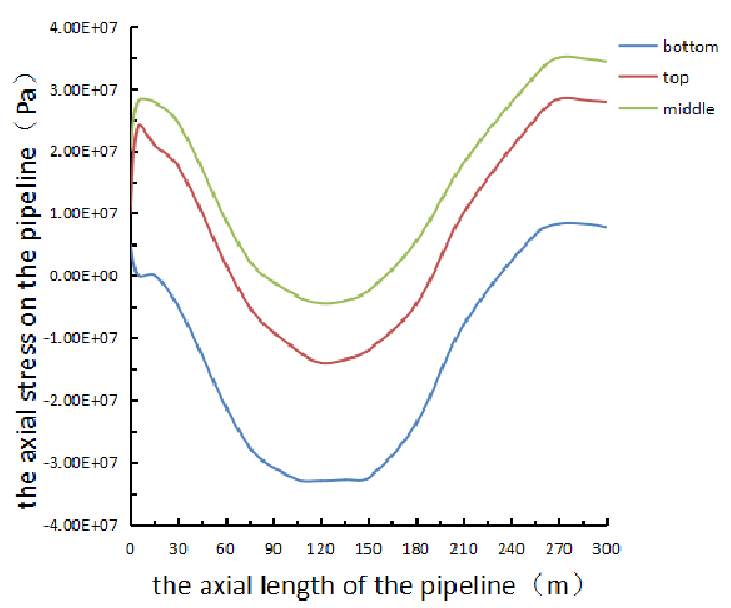

(b) 


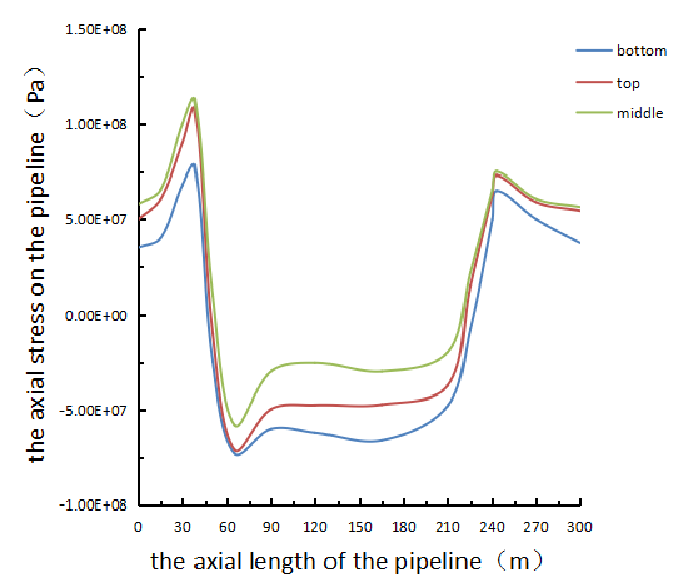

(c)

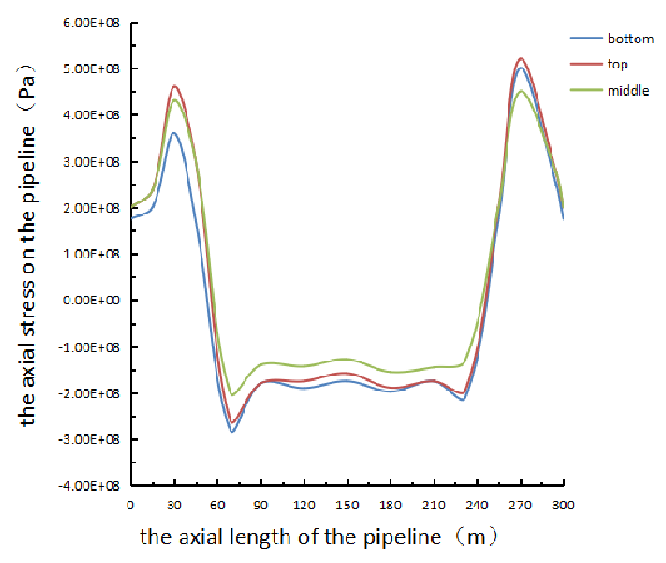

(d)

Fig.3 Axial stress distribution on the pipeline at different excavation stages

\section{The stress distribution in different parts of the pipeline section}

In order to study the different parts of the stress distribution of the pipeline section, the top, middle and bottom of three parts are selected. After mining the fourth step (in Fig.3(a)), the middle of the pipeline is in a state of tensile stress. The bottom of the pipeline is in a state of compressive stress. The top of the pipeline in the mined out area $(75 \mathrm{~m}-135 \mathrm{~m})$ is in a state of tensile stress, while the top of the pipeline in other locations is in a state of compressive stress.

After mining the fifth step (in Fig.3(b)), The top, middle and bottom parts of the pipeline are in both tensile and compression state. The compressive stress zones at the top, middle and bottom of the pipeline is in the axial direction $(63 \mathrm{~m}-180 \mathrm{~m}),(78 \mathrm{~m}-165 \mathrm{~m})$ and $(18 \mathrm{~m}-223 \mathrm{~m})$ respectively. There is still tensile stress zone in the top and middle part of the pipeline in the gob. There is still compressive stress in the bottom of the pipeline outside the gob, which shows that the stress distribution of the pipeline are inconsistent with the distribution of the stretching and compression of the mining mobile basin[10].

After mining the sixth step (in Fig.3(c)), the top, middle and bottom parts of the pipeline are subjected to both tensile and compressive stresses, and the tensile stress at the top and middle parts of the pipeline are approximately equal and are higher than the tensile stresses at the bottom part. The pipeline compressive stress sorted by size is bottom, top and middle. The outer side of the mined out area $(45 \mathrm{~m}-225 \mathrm{~m})$ is pulled and pressed internally, which shows that the stress distribution on the pipeline are inconsistent with the distribution of the stretching and compression of the mining mobile basin.

After mining the seventh step (in Fig.3(d)), the pipeline stress is similar to the sixth step of mining. The possible damage to the pipe section due to peak tensile stresses is at the top, the middle and the bottom in turn, and the possible damage to the pipe section due to peak compressive stresses is at the bottom, the top and the middle in turn. The pipeline outside the goaf is pulled on the whole and the inner part is compressed on the whole, which shows that the stress distribution of the pipeline is consistent with the distribution of the stretching and compression of the mining mobile basin.

\section{Conclusions}

In this paper, a numerical simulation method of finite difference method is used to simulate the stress distribution of pipelines at different stages of longwall mining in the Shanxi section of the west-east gas pipeline project. The following conclusions are obtained

(1) The axial stress of the pipeline is closely related to the advancing distance of the working face. As the advancing distance increases, the axial stress of the pipeline undergoes three stages, namely, 
stress gradually increasing stage to the stress concentration stage, and then the local stress exceeding limitation stage. In the first stage, the MTS on the pipeline is only $8.1 \%$ of allowable stress. In the second stage, three stress concentration zones occur, in which the MTS on the pipeline accounts for $25.6 \%$ of the allowable stress. Monitoring should be strengthened at this stage. In the third stage, pipe lifting and other emergency treatments should be carried out.

(2)The possible damage to the pipeline occurs at the two peak tensile stresses, which are at the outer edge of gob (15m apart from the first cut, $14 \mathrm{~m}$ from stopping line), then at the two peak compressive stresses, which are at the inner edge of gob $(24 \mathrm{~m}$ from the first cut, $23 \mathrm{~m}$ from the stopping line). The possible damage to the pipe section due to the MTS is at the top, the middle and the bottom in turn, and the possible damage to the pipe section due to the MCS is at the bottom, the top and the middle in turn

(3)The stress state of the pipeline is not completely consistent with the distribution of the tensile and compression zones in the mining mobile basin. In the first stage, pipeline stress distribution and mining moving basin is inconsistent. In the second and third stages, the whole pipeline of the outer edge zone of the goaf is pulled, and the whole pipeline in the goaf is compressed, which is consistent with the characteristics of the tensile and compression zone of the mining mobile Basin.

\section{Acknowledgements}

This work was supported by the National Science Foundation of China (No.41172266), and Evaluation of Mine Geological Disaster Control Effect and Management Support Capability Construction (No.12120113008000, No.12120113007000) and the One Hundred Excellent Young Talents for Ministry of Land and Resources of China (No.2007). Thanks are due to China Petroleum Pipeline Engineering Corporation for providing the details of the mine and the pipeline. Acknowledgements are also due to Dr. Jianzhong Huang for providing the monitoring data.

\section{References}

[1] Hong WANG, Mi ZHANG, CHANG Huai-min. Petroleum Engineering Construction (In Chinese), Vol.34 (2)(2008): 23- 26.

[2] ZHU Kun. Coal Mining Technology (In Chinese),Vol.15 (2) (2010): 41 - 43.

[3] S.S. Peng, Luoy. Mining Science and Technology, Vol.6 (2) (1988), p.205

[4] Dearman W.R., Strachan Anne, Roche D.P., and Vincet. Bulletin of the International Association of Engineering Geology, Vol.25 (1982), p.19

[5] Hucka V J, Blair C K, Kimball E P. Mining Engineering, Vol.38 (10) (1986), p. 980

[6] X.L. Wang, J. Shuai, J.Q. Zhang. Rock and Soil Mechanics (In Chinese). Vol.32 (11) (2011), p.3378

[7] G.M. Cheng, W.P. Li, Z.F. Guo. Coal Mining Technology (In Chinese). Vol.15 (4) (2010), p.31

[8] G.M. Cheng, Z.P. Zhang. Coal Mining Technology (In Chinese). Vol.16 (5) (2011), p.35

[9] G.M. Cheng, K.Y Wang. Science Technology and Engineering (In Chinese). Vol.16 (22) (2016), p.307

[10] FENG Wei, YAO Huiquan. Hydrogeology and Engineering Geology(In Chinese),

Vol.37(3)(2010): 112-115. 